\title{
Obsessive-compulsive traits in children and adolescents with Asperger syndrome
}

\author{
Liliana Ruta · Diego Mugno · \\ Valentina Genitori D'Arrigo • \\ Benedetto Vitiello $\cdot$ Luigi Mazzone
}

Received: 3 June 2008/ Accepted: 26 May 2009/Published online: 26 June 2009

(C) Springer-Verlag 2009

\begin{abstract}
The objective of this study is to examine the occurrence and characteristic features of obsessive-compulsive behaviours in children and adolescents with Asperger syndrome (AS), with respect to a matched obsessive compulsive disorder group (OCD) and a typically developing control group (CG). For this purpose, 60 subjects (20 OCD; 18 AS; 22 CG), aged 8-15 years, matched for age, gender and IQ were compared. AS and OCD patients were diagnosed according to the DSM-IV-TR criteria. The Autism Diagnostic Interview-Revised and the Autism Diagnostic Observation Schedule were used to assist in the AS diagnosis; the WISC-R was administered to assess IQ. Obsessive and compulsive symptoms were evaluated by using the Children's Yale-Brown Obsessive-Compulsive Scale (CYBOCS). None of the AS children received a formal diagnosis of OCD. The AS group presented significantly higher frequencies of Hoarding obsessions and Repeating, Ordering
\end{abstract}

L. Ruta $(\bowtie) \cdot$ D. Mugno - V. G. D’Arrigo - L. Mazzone

Division of Child Neurology and Psychiatry,

Department of Paediatrics, University of Catania,

Via S. Sofia, 78, 95123 Catania, Italy

e-mail: ruta@policlinico.unict.it

D. Mugno

e-mail: diegomugno@yahoo.it

V. G. D'Arrigo

e-mail: valentina.genitori@ libero.it

L. Mazzone

e-mail: gigimazzone@yahoo.it

B. Vitiello

Child and Adolescent Treatment and Preventive Interventions

Research Branch, National Institute of Mental Health,

MSC 9633, Room 7147, 6001 Executive Blvd.,

Bethesda, MD, USA

e-mail: bvitiell@mail.nih.gov and Hoarding compulsions compared to CG. The OCD group, in turn, reported significantly higher frequencies of Contamination and Aggressive obsessions and Checking compulsions compared to both the AS group and CG. As expected, the OCD group displayed a higher severity of symptoms (Moderate level of severity) than did the AS group (Mild level of severity). Finally, in our sample, neither the OCD group nor the AS group demonstrated a completely full awareness of the intrusive, unreasonable and distressing nature of symptoms, and the level of insight did not differ between the OCD group and CG, although an absence of insight was observed in the AS group. Children with AS showed higher frequencies of obsessive and compulsive symptoms than did typically developing children, and these features seem to cluster around Hoarding behaviours. Additionally, different patterns of symptoms emerged between the OCD and AS groups. Finally, in our sample, the level of insight was poor in both the OCD and the AS children. Further research should be conducted to better understand the characteristics of repetitive thoughts and behaviours in autism spectrum disorders, and to clarify the underlying neurobiological basis of these symptoms.

Keywords Asperger syndrome $\cdot$ Autism .

Obsessive-compulsive disorder - Repetitive behaviours . Insight

\section{Introduction}

Asperger syndrome (AS) is a neurodevelopmental disorder characterized by debilitating deficits in social-communicative skills and a restricted and repetitive pattern of interests and behaviours, but without the symptoms of mental retardation and clinically significant language delay 
which are characteristic of classic autism. It falls under the category of autism spectrum disorders (ASD), together with autism (AD), pervasive developmental disorder not otherwise specified (PDD-NOS), disintegrative disorder and Rett syndrome [2].

Restricted, repetitive and stereotyped patterns of behaviour as well as impairment in social interaction and communication are characteristic disabling features and represent the main core domains of ASD [10, 17]. In particular, the range of repetitive interests and activities observed within the autism spectrum is broad and heterogeneous [7, 26] and shows a different phenomenology, especially between lower-functioning autism and highfunctioning autism [8, 33]. Overall, these behaviours include motor mannerisms and stereotypies, strict adherence to routines, need of sameness, persistent preoccupation with parts of objects, rituals in daily life, idiosyncratic circumscribed interests or abilities and obsessive hyperfocusing on very specific, often odd, details, the latter being particularly characteristic of AS [31]. Clinicians and researchers often refer to these behaviours broadly in terms of obsessive and compulsive traits.

Obsessive-compulsive disorder (OCD) is defined in the DSM-IV-TR as the presence of recurrent and persistent thoughts, impulses or images-obsessions-that cause marked anxiety or distress. The person attempts to neutralize such obsessions by performing certain action or ritual, defined as compulsions. Typically, the disorder interferes significantly with daily routines and occupational or academic functioning, and impairs social and familial relationships $[2,27]$.

Higher prevalence of autistic traits has been found in OCD samples both in adults [5, 6] and children [16], and some evidence suggests that treatments effective for OCD may be effective for repetitive thoughts and behaviours in ASD as well $[15,19,24,25]$. Also, family studies have reported an association between restrictive or repetitive behaviours in probands with autism and obsessive-compulsive features in parents both in multiplex [14] and sporadic autism families [1]. Taken together, these evidences point clearly to a link between and a partial overlap of the two disorders. However, the application of OCD concepts to the autism spectrum in terms of diagnostic category or dimensional domain is currently controversial.

Indeed, even if the clinical phenomenology of OCD symptoms may be similar in the two groups, individuals with ASD tend not to show distress associated with their fixed beliefs and do not perform rituals to alleviate anxiety. It is further assumed that they might have little awareness about the senseless, excessive and unreasonable nature of their repetitive thoughts and behaviours (insight), partially due to autistic individuals' impaired ability to process and talk about their own internal state of mind [3].
However, even if insight represents a defining feature of OCD in adulthood, the degree of egodystonicity of the symptoms may differ and this requirement, according to the DSM-IV, does not apply to children with OCD, who may lack sufficient cognitive awareness to make this judgment $[12,28]$.

Systematic comparisons of repetitive behaviours in children with ASD and OCD have been limited. In one study [23], the Yale-Brown Obsessive Compulsive Scale (Y-BOCS) was used to identify the presence of "Hoarding", "Touching/Tapping/Rubbing", "Self-damaging" and the absence of "Aggressive", "Symmetry", "Checking" and "Counting" in order to predict the ASD membership, and a different pattern of OC symptoms was reported to be endorsed by the two groups. Nonetheless, part of the between-group differences might be accounted for by a discrepancy in IQ (mean IQ $=69.7$ in ASD versus normal IQ in OCD) and by significant language impairment in a sub-group of ASD subjects ( 15 of them were nonverbal).

Another study [29], also on adults, addressed high functioning autism (HFA) and AS, comparing them to a sample of OCD patients. The authors found a similar pattern of obsessions and compulsions in the HFA/AS and OCD groups, with $25 \%$ of HFA/AS subjects receiving a formal diagnosis of OCD according to ICD-10 criteria [35].

A recent study [9] focused on symptom overlap amongst ASD, OCD and social anxiety disorder in adults, reporting that subjects with only OCD scored highest on OC symptom severity, with co-morbid ASD subjects scoring at an intermediate level between OCD subjects and controls. There were no differences in insight between OCD subjects with and without ASD.

To the authors' knowledge, the only study addressing childhood [36] compared HFA and OCD children on a range of repetitive behaviours. For the purpose of the study, Zandt et al. administered the Repetitive Behaviour Questionnaire (RBQ) and the Children's Y-BOCS (CY-BOCS) as a complement to the RBQ. On the RBQ, OCD and AS children showed similar rates on repetitive and sameness behaviour and repetitive movements. However, whilst sameness behaviour occurred at significantly higher rates in younger children with OCD compared to older children with the disorder, age was not significantly related to sameness behaviour or repetitive movements in children with HFA, remaining relatively stable over time. On the CY-BOCS Checklist, the OCD group reported more frequent and more sophisticated obsessions and compulsions than the HFA group and both groups showed more obsessions and compulsions than a typically developing comparison group.

In relation to the limited literature data, the rationale for this study was to systematically investigate the presence of obsessive-compulsive traits in children with ASD. We assumed that some children and adolescents with AS might 
present peculiar patterns and distressing levels of obsessive and compulsive symptoms, possibly underestimated because of a lack of focus on this specific psychopathological feature. Hence, the purpose of our study was (1) to examine the occurrence and characteristic features in type, frequency and severity of obsessive and compulsive behaviours in children and adolescents with AS, in a matched OCD and typically developing group and (2) to compare the rate of insight amongst children and adolescents with OCD with or without AS.

In particular, we hypothesized that (1) children and adolescents with AS might experience a higher rate of OC symptoms, compared to typically developing children; (2) AS and OCD patients might endorse different patterns of obsessions and compulsions; (3) the OCD group might show higher severity of symptoms and (4) the OCD group might display better insight than the AS group.

\section{Method}

\section{Participants and diagnosis}

Sixty consecutive children and adolescents (20 affected by OCD; 18 affected by AS; 22 healthy, typically developing controls), aged $8-15$ years, were evaluated by a boardcertificated child and adolescent neuropsychiatrist (LR), in the Ambulatory Unit of Child and Adolescent Neuropsychiatry at the University Hospital of Catania, Italy, in the period between October 2006 and September 2007. The OCD and AS patients had been first diagnosed according to the DSM IV-TR criteria and regularly followed up at the University Hospital of Catania by a multi-professional team comprising experienced board-certified child psychiatrists and clinical psychologists. A total of 12 subjects with OCD and 8 with AS enrolled into the study had been referred to the Ambulatory Unit of Child and Adolescent Neuropsychiatry of the University Hospital of Catania by their paediatricians, whereas the parents of 8 children with OCD and 10 with AS were recommended for a consultation with a child psychiatrist by the school counselling service. The control group (CG) was recruited from a large public mainstream school (primary and secondary) in the city centre of Catania, attended by multi-cultural pupils. A random selection of 100 pupils from a population of 725 children aged 8-15 was conducted and a detailed information sheet was sent out to the families. Those who agreed to participate $(n=33)$ came to the Ambulatory Unit of Child and Adolescent Neuropsychiatry of the University Hospital of Catania to be evaluated. A total of 11 subjects were excluded from the study due to ineligibility for participation ( 3 for a history of learning disabilities, 2 for a history of psychomotor retardation, 3 for having epilepsy $(n=1)$ or a positive history of seizures $(n=2), 1$ because of a familiar history of ASD and 2 for showing borderline symptoms of ADHD).

The Kiddie-Schedule for Affective Disorders and Schizophrenia-Present and Lifetime Version (K-SADS-PL) [18] was used to confirm the diagnosis in the OCD sample and to exclude subjects with a psychiatric condition from the CG, whereas the Autism Diagnostic Interview-Revised [21], the Autism Diagnostic Observation Schedule [20] and the Asperger Syndrome Diagnostic Interview [13] were used as part of the AS diagnostic assessment.

For the purpose of the study, all the children and adolescents diagnosed with mental retardation and neurological diseases (such as epilepsy or a history of seizures, psychomotor retardation and regression, language delay, tuberous sclerosis, fragile- $X$ syndrome, etc.) were excluded. Due to the small size of the sampling groups and the inability to further split the groupings, the authors decided not include in the clinical sample children with ADHD and/ or Tic disorder comorbidity, thereby reducing the possible influence of these conditions on the OC symptoms and providing maximal intra-group homogeneity.

None of the AS children received a formal diagnosis of OCD or showed clinical symptoms of ADHD and/or Tics or Tourette's syndrome.

None of the subjects had ever used any psychotropic medication, nor were they undergoing any psychological therapy at the time of the study.

\section{Procedures}

The ethics committee of the University Hospital of Catania approved the study design.

A detailed information sheet was provided in person and broadly discussed with the participants' parents when they came to the Ambulatory Unit willing to participate in the study and those who accepted to take part in the research signed a consent form before beginning testing. Written assent was also obtained from children and adolescents. No payment and/or reimbursement for participation in the study were provided.

The principal socio-demographic characteristics of the families were investigated. All were biological parents of Italian ethnicity. Parental education level (classified as "University degree", "High school Diploma", "some high school", "Elementary school") and parental occupation ("Unskilled job", "Skilled manual job", "low-skilled nonmanual job", "Upper-level executive employment", "Selfemployed", "Unemployed") did not significantly differ amongst the three groups $\left(\chi^{2}=0.95, p=0.81\right.$ and $\chi^{2}=1.59, p=0.66$, respectively).

The Wechsler Intelligence Scale for Children-Revised (WISC-R) [34] assessed the Full-scale, Verbal and 
Performance Intelligent Quotient (FIQ; VIQ; PIQ) scores in all the subjects.

To measure thoroughly the broad range of persistent, obsessive thoughts, rituals and repetitive behaviours, all participants were administered the CY-BOCS [30]. Both children and parents were directly interviewed and firsthand observations of the children's behaviour were conducted by the principal investigator (LR), who was specifically trained before the study. To ensure reliability of the ratings, an experienced, trained psychologist, blind to the diagnosis, interviewed independently the parents and the children and a high inter-rater agreement was obtained (Cohen's Kappa coefficient $=0.91$ ).

The CY-BOCS consists of a clinician-rated inventory and a severity scale. Symptoms are classified in eight categories for Obsessions (Contamination, Aggressive, Sexual, Saving/Hoarding, Superstition, Somatic, Religious, Miscellaneous) and nine categories for Compulsions (Cleaning, Checking, Repeating, Counting, Ordering, Hoarding, Magical, Other person, Miscellaneous); the Target Symptom List is generated by asking the subjects about specific obsessions and compulsions and through observation during the interview. A dichotomous rating (endorsed if present) for current (displayed within the past month) and past symptoms is assigned.

The second part of the scale, called the CY-BOCS Severity Rating Scale, is a 10-item clinician-administered scale that scores the severity of symptoms reported to the CY-BOCS Checklist; the Total Score (range 0-40) reflects the composite effect of the average occurrence of obsessions and compulsions in five different items: Time Spent, Interference, Distress, Resistance and Control. Moreover, five progressive Ranges of Severity are obtained by the Total Score: Sub-clinical level (score 0-7), Mild level (score 8-15), Moderate level (score 16-23), Severe level (score 24-31) and Extreme level (score 32-40).

Insight is measured by a single investigational item (\# 11) on the CY-BOCS. The item is regularly administered in clinical practise and has been used in past research $[22,32]$ to supply essential information in a dimensional perspective about the senselessness or excessiveness of beliefs expressed at the time of the interview. It provides specific probes like: "Do you think your concerns or behaviors are reasonable? What do you think would happen if you did not perform the compulsion(s)? Are you convinced something would really happen?" Interviewer ratings range from 0 (Excellent) to 4 (Absent).

\section{Statistical analysis}

Data analysis was performed using the Statistical Package for Social Sciences (SPSS 11.0 for Mac OS-X). Both descriptive and inferential analyses were undertaken. Chi- square analyses and Fisher's exact test (FET) were implemented when the expected count was $<5$ for dichotomous variables, and one-way ANOVAs with post-hoc Scheffé multiple comparison $t$-tests were conducted for continuous variables. Test results exceeding a threshold of $p<0.05$ were regarded as statistically significant.

\section{Results}

Demographic characteristics of the sample

The AS group $(N=18)$ included $16(89 \%)$ males and 2 (11\%) females aged 8-14 years $($ mean $=10.61 \pm$ 1.91 years), and the OCD group $(N=20)$ consisted of 16 (80\%) males and 4 (20\%) females aged 8-15 years (mean $=11.65 \pm 1.69$ years), whereas the control group $(\mathrm{CG} ; N=22)$ included $17(77 \%)$ males and $5(23 \%)$ females aged $8-15$ years (mean $=10.68 \pm 2.01$ years); the three groups did not significantly differ in sex ratio $\left(\chi^{2}=0.95, d f=2, p=0.6\right)$ or age $(F=1.89, d f=2$, $p=0.16$ ).

All the subjects showed comparable FIQ $(F=1.80$, $p=0.17)$, VIQ $(F=1.25, p=0.29)$ and PIQ $(F=2.13$, $p=0.13$ ) with higher average VIQ scores than PIQ scores. A similar degree of difference between VIQ and PIQ was detected amongst the three groups $(F=0.69, p=0.51$, post-hoc Scheffé $t$-tests for group comparisons n.s.). Table 1 documents the demographic characteristics of the sample and the IQ scores.

\section{Repetitive behaviour types and severity}

Significant differences amongst the three groups were obtained for Contamination $\left(\chi^{2}=17.67, \quad d f=2\right.$, $p=0.000)$, Aggressive $\left(\chi^{2}=14.25, d f=2, p=0.001\right)$, Sexual $\left(\chi^{2}=6.32, d f=2, p=0.043\right)$, Saving/Hoarding $\left(\chi^{2}=6.50, d f=2, p=0.039\right)$ and Somatic $\left(\chi^{2}=6.15\right.$, $d f=2, p=0.046)$ obsessions and Cleaning $\left(\chi^{2}=17.16\right.$, $d f=2, \quad p=0.000)$, Checking $\left(\chi^{2}=17.77, \quad d f=2\right.$, $p=0.000)$, Repeating $\left(\chi^{2}=15.44, d f=2, p=0.000\right)$, Ordering $\left(\chi^{2}=10.22, \quad d f=2, p=0.006\right)$, Hoarding $\left(\chi^{2}=7.49, \quad d f=2, \quad p=0.024\right)$ and Other person $\left(\chi^{2}=10.37, d f=2, p=0.006\right)$ compulsions. The frequencies and type of symptoms at the CY-BOCS Checklist in the three groups are displayed in Fig. 1.

Two-by-two comparisons between groups revealed that the AS children, with respect to the CG, reported significantly higher frequencies in the following categories: Saving/Hoarding (AS: $44 \%$ vs. CG: $9 \%$, FET, $p=0.02$ ) obsessions and Repeating (AS: $56 \%$ vs. CG: $4 \%$, FET, $p=0.001$ ), Ordering (AS: $56 \%$ vs. CG: $9 \% \chi^{2}=10.18$, $d f=1, p=0.001$ ) and Hoarding (AS: $28 \%$ vs. CG: $0 \%$, 
Table 1 Descriptive characteristics of the sample

\begin{tabular}{|c|c|c|c|c|c|c|c|}
\hline Subjects & $\begin{array}{l}\text { Age } \\
{[\text { Mean (SD)] }}\end{array}$ & $\begin{array}{l}\text { Males } \\
{[n(\%)]}\end{array}$ & $\begin{array}{l}\text { Females } \\
{[n(\%)]}\end{array}$ & $\begin{array}{l}\text { FIQ } \\
\text { [Mean (SD)] }\end{array}$ & $\begin{array}{l}\text { VIQ } \\
\text { [Mean (SD)] }\end{array}$ & $\begin{array}{l}\text { PIQ } \\
\text { [Mean (SD)] }\end{array}$ & $\begin{array}{l}\text { VIQ - PIQ } \\
{[\text { Mean (SD)] }}\end{array}$ \\
\hline $\operatorname{OCD}(N=20)$ & 11.65 (1.69) & $16(80)$ & $4(20)$ & $95.60(6.78)$ & 98.95 (5.65) & 93.85 (7.67) & $5.1(9.28)$ \\
\hline $\mathrm{AS}(N=18)$ & $10.61(1.91)$ & $16(89)$ & $2(11)$ & 91.89 (7.66) & $94.89(11.03)$ & $89.94(6.30)$ & $4.95(12.18)$ \\
\hline $\mathrm{CG}(N=22)$ & $10.68(2.01)$ & $17(77)$ & $5(23)$ & $95.68(6.71)$ & $96.09(7.46)$ & $94.91(9.04)$ & $1.18(14.44)$ \\
\hline
\end{tabular}

FET, $p=0.013$ ) compulsions. Slightly higher but not statistically significant frequencies were displayed by the AS group as compared to OCD group on Saving/Hoarding (AS: $44 \%$ vs. OCD: $30 \%, \chi^{2}=0.85, p=0.36$ ) obsessions and Ordering (AS: $56 \%$ vs. OCD: $40 \%, \chi^{2}=0.92$, $p=0.34$ ) and Hoarding (AS: $28 \%$ vs. OCD: $10 \%$, FET, $p=0.22$ ) compulsions.

The OCD group reported, with respect to the AS group, significantly higher frequencies in Contamination (OCD: $70 \%$ vs. AS: $\left.27 \%, \chi^{2}=6.76, p=0.022\right)$ and Aggressive (OCD: $45 \%$ vs. AS: $5 \%$, FET, $p=0.009$ ) obsessions and Checking (OCD: $65 \%$ vs. AS: $17 \%, \chi^{2}=9.08, p=0.003$ ) compulsions.

Table 2 shows the frequencies and the contrasts between groups on the CY-BOCS Checklist.

The average Total Severity Score was 22.05 $(\mathrm{SD}=5.49)$ for OCD group (Moderate range of severity), 15 ( $\mathrm{SD}=6.33)$ for AS subjects (Mild clinical impairment) and $2.05(\mathrm{SD}=1.81)$ for $\mathrm{CG}$ (Sub-clinical level), with a significant difference between the three groups $(F=93.44$, $d f=2, p=0.000$; all post-hoc Scheffé $t$-tests for group comparisons: $p=0.000$ ).

Insight

Referring to Item 11 of the CY-BOCS to investigate the insight in OCD and AS groups, we found that none of the participants had an Excellent Insight level. No statistically significant differences were displayed between OCD and AS patients for Good (15\% of OCD vs. $0 \%$ of AS, FET, $p=0.23$ ), Fair (50\% of OCD vs. $22 \%$ of AS, $\chi^{2}=3.14$, $d f=1, p=0.076$ ) and Poor (20\% of OCD vs. $33 \%$ of AS, FET, $\mathrm{p}=0.47)$ insight whilst the AS group exhibited higher frequencies of endorsement for Absent (15\% of OCD vs. $44 \%$ of AS, $\chi^{2}=3.99, d f=1, p=0.046$ ). Figure 2 shows the distribution of frequencies in the samples, in relation to different levels of insight, from Excellent to Absent.

\section{Discussion}

The results suggest that children and adolescents with AS showed higher frequencies of obsessive and compulsive

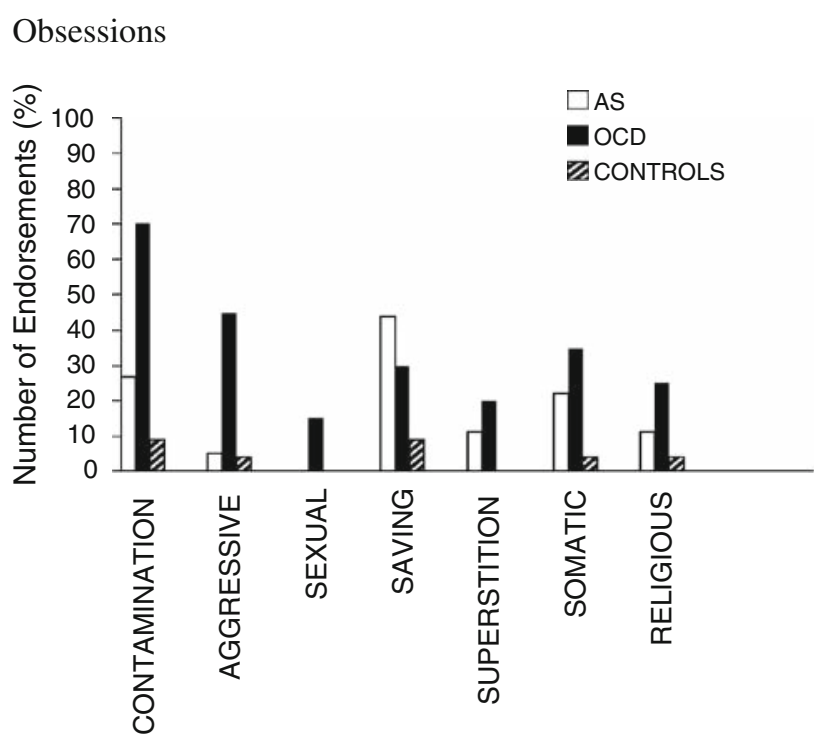

Compulsions

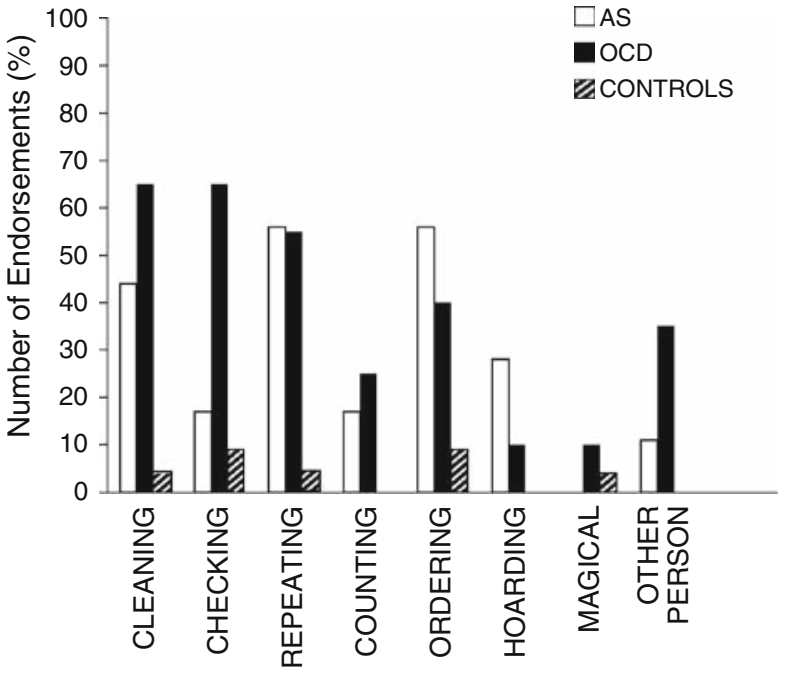

Fig. 1 Types and frequencies of symptoms measured by the CYBOCS Checklist

symptoms than typically developing children, significant for Saving/Hoarding, Repeating and Ordering categories. This finding is in line with our expectation from the first hypothesis and reasonably consistent with those reported in 
Table 2 Types and frequencies of obsessions and compulsions measured by the CY-BOCS Checklist

\begin{tabular}{|c|c|c|c|c|c|c|}
\hline Symptoms & $\begin{array}{l}\text { OCD } \\
(N=20)[n(\%)]\end{array}$ & $\begin{array}{l}\mathrm{AS}(N=18) \\
{[n(\%)]}\end{array}$ & $\begin{array}{l}\mathrm{CG}(N=22) \\
{[n(\%)]}\end{array}$ & $\chi^{2}(d f=1)$ & Contrasts & $p$ \\
\hline \multicolumn{7}{|l|}{ Obsessions } \\
\hline \multirow[t]{3}{*}{ Contamination } & $14(70)$ & $5(27)$ & $2(9)$ & 6.76 & $\mathrm{OCD}>\mathrm{AS}^{*}$ & 0.009 \\
\hline & & & & 16.48 & $\mathrm{OCD}>\mathrm{CG}^{*}$ & 0.000 \\
\hline & & & & 2.4 & $\mathrm{AS}=\mathrm{CG}$ & $0.21^{\mathrm{a}}$ \\
\hline \multirow[t]{3}{*}{ Aggressive } & $9(45)$ & $1(5)$ & $1(4)$ & 7.6 & $\mathrm{OCD}>\mathrm{AS}^{*}$ & $0.009^{\mathrm{a}}$ \\
\hline & & & & 9.45 & $\mathrm{OCD}>\mathrm{CG}^{*}$ & $0.003^{\mathrm{a}}$ \\
\hline & & & & 0.02 & $\mathrm{AS}=\mathrm{CG}$ & $1^{\mathrm{a}}$ \\
\hline \multirow[t]{3}{*}{ Sexual } & $3(15)$ & 0 & 0 & 2.93 & $\mathrm{OCD}=\mathrm{AS}$ & $0.232^{\mathrm{a}}$ \\
\hline & & & & 3.55 & $\mathrm{OCD}=\mathrm{CG}$ & $0.099^{\mathrm{a}}$ \\
\hline & & & & - & $\mathrm{AS}=\mathrm{CG}$ & - \\
\hline \multirow[t]{3}{*}{ Saving/hoarding } & $6(30)$ & $8(44)$ & $2(9)$ & 0.85 & $\mathrm{OCD}=\mathrm{AS}$ & 0.357 \\
\hline & & & & 2.97 & $\mathrm{OCD}=\mathrm{CG}$ & $0.123^{\mathrm{a}}$ \\
\hline & & & & 6.6 & $\mathrm{AS}>\mathrm{CG}$ & $0.025^{\mathrm{a}}$ \\
\hline \multirow[t]{3}{*}{ Somatic } & $7(35)$ & $4(22)$ & $1(4)$ & 0.75 & $\mathrm{OCD}=\mathrm{AS}$ & 0.386 \\
\hline & & & & 6.3 & $\mathrm{OCD}>\mathrm{CG}$ & $0.018^{\mathrm{a}}$ \\
\hline & & & & 2.82 & $\mathrm{AS}=\mathrm{CG}$ & $0.155^{\mathrm{a}}$ \\
\hline \multicolumn{7}{|l|}{ Compulsions } \\
\hline \multirow[t]{3}{*}{ Cleaning } & $13(65)$ & $8(44)$ & $1(4)$ & 1.62 & $\mathrm{OCD}=\mathrm{AS}$ & 0.203 \\
\hline & & & & 17.23 & $\mathrm{OCD}>\mathrm{CG}^{*}$ & 0.000 \\
\hline & & & & 9.04 & $\mathrm{AS}>\mathrm{CG}^{*}$ & $0.006^{\mathrm{a}}$ \\
\hline \multirow[t]{3}{*}{ Checking } & $13(65)$ & $3(17)$ & $2(9)$ & 9.08 & $\mathrm{OCD}>\mathrm{AS}^{*}$ & 0.003 \\
\hline & & & & 14.26 & $\mathrm{OCD}>\mathrm{CG}^{*}$ & 0.000 \\
\hline & & & & 0.52 & $\mathrm{AS}=\mathrm{CG}$ & 0.64 \\
\hline \multirow[t]{3}{*}{ Repeating } & $11(55)$ & $10(56)$ & $1(4)$ & 0.001 & $\mathrm{OCD}=\mathrm{AS}$ & 0.973 \\
\hline & & & & 13.07 & $\mathrm{OCD}>\mathrm{CG}^{*}$ & 0.000 \\
\hline & & & & 12.92 & $\mathrm{AS}>\mathrm{CG}^{*}$ & 0.001 \\
\hline \multirow[t]{3}{*}{ Ordering } & $8(40)$ & $10(56)$ & $2(9)$ & 0.92 & $\mathrm{OCD}=\mathrm{AS}$ & 0.338 \\
\hline & & & & 5.52 & $\mathrm{OCD}>\mathrm{CG}$ & $0.03^{\mathrm{a}}$ \\
\hline & & & & 10.18 & $\mathrm{AS}>\mathrm{CG}^{*}$ & 0.001 \\
\hline \multirow[t]{3}{*}{ Hoarding } & $2(10)$ & $5(28)$ & 0 & 1.99 & $\mathrm{OCD}=\mathrm{AS}$ & $0.22^{\mathrm{a}}$ \\
\hline & & & & 2.31 & $\mathrm{OCD}=\mathrm{CG}$ & $0.22^{\mathrm{a}}$ \\
\hline & & & & 6.98 & $\mathrm{AS}>\mathrm{CG}$ & $0.013^{\mathrm{a}}$ \\
\hline \multirow[t]{3}{*}{ Other person } & $7(35)$ & $2(11)$ & 0 & 2.99 & $\mathrm{OCD}=\mathrm{AS}$ & $0.13^{\mathrm{a}}$ \\
\hline & & & & 9.24 & $\mathrm{OCD}>\mathrm{CG}^{*}$ & $0.003^{\mathrm{a}}$ \\
\hline & & & & 2.57 & $\mathrm{AS}=\mathrm{CG}$ & $0.196^{\mathrm{a}}$ \\
\hline
\end{tabular}

$* p<0.01$

${ }^{\text {a }}$ Fisher's exact test

an earlier study [36], which found that children with OCD and ASD reported more obsessions and compulsions than typically developing children. Furthermore, previous studies related Hoarding behaviour, amongst other symptoms, to a variety of neurological and psychiatric conditions, including autism [11] and our data may confirm this relationship.

Consistent with our second hypothesis, children and adolescents with AS and OCD engaged in different types and frequencies of repetitive thoughts and behaviours. Specifically, the OCD group reported significantly higher frequencies of Contamination and Aggressive obsessions and Checking compulsions compared to the AS group and the AS group in turn displayed slightly higher (but not statistically significant) frequencies of Saving/Hoarding and Ordering clusters compared to OCD group. Our results mirror those of McDougle et al. [23] showing peculiar obsessions including Contamination, Aggressive and Symmetry and compulsions such as Checking and Cleaning in adults with OCD, and Hoarding and Ordering behaviours in adults with ASD. In our sample, the latter finding has not been confirmed by a statistically significant difference, but AS children nevertheless displayed a higher frequency of Hoarding symptoms as well. The absence of a significant 


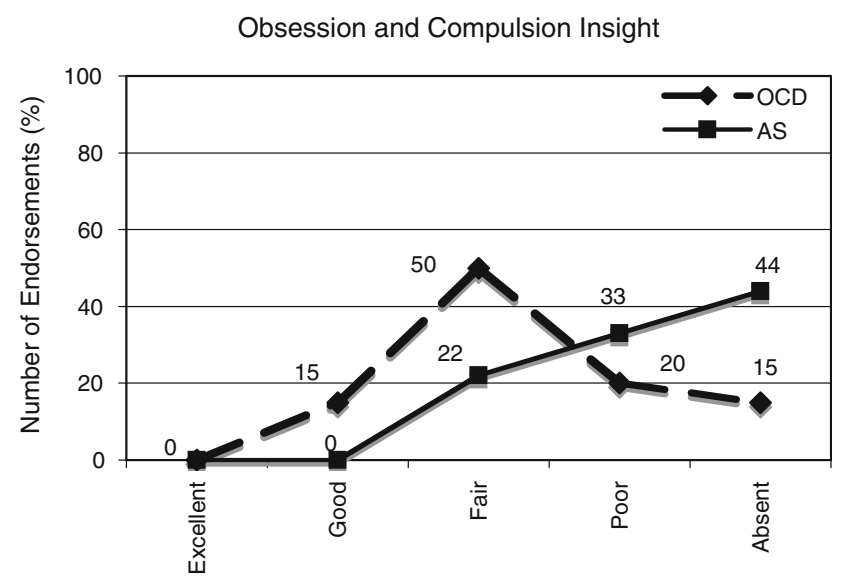

Fig. 2 Levels of insight assessed using the C-YBOCS in the OCD and AS group (\%)

difference in Hoarding and Ordering symptoms could well be the result of a small sample size and therefore low statistical power.

As we expected from the third hypothesis, the severity of OC symptoms was significantly higher not only in the OCD group (Moderate range of severity) but also amongst the AS children, who demonstrated a Mild clinical impairment. This finding is in line with the Cath study [9], which reported that Y-BOCS scores of co-morbid ASD subjects were intermediate between patients with only OCD and controls, with the patients with only OCD scoring the highest.

In contrast with the final hypothesis, no differences were found between AS and OCD children on the degree of egodystonicity of the repetitive symptoms, except for the level of insight Absent where AS children were significantly more represented. The latter finding might be accounted for by a specific difficulty in some AS children, more likely than OCD children, to properly attribute their beliefs and fixed rituals possibly due to a partial impairment in processing and talking about their own internal state of mind. Nevertheless, we find it noteworthy that nobody in our sample, either in the OCD group or in the AS group, displayed Excellent insight and that most of the subjects in both groups showed Fair or Poor insight. These results might be related in both groups to the age and the level of development and concord with previous findings, which suggested the existence in childhood OCD of some impairments in perceiving, processing and describing repetitive thoughts and behaviours [12, 27]. Also, the finding of no difference in insight amongst the two groups is in line with the study by Cath et al., which pointed out that egodystonicity did not discriminate between OCD and ASD subjects [9] and with the data of Ivarsson et al., who found in a paediatric OCD sample no relationship between the OCDpatients' level of insight and the presence of ASD traits [16].
Our study demonstrated various limitations. First, even if the CY-BOCS is a relatively quick clinician-rated instrument, it has been specifically designed for children diagnosed with OCD. Nevertheless, being that our AS subjects had no language impairment, we found that they were fairly well able to describe fixed thoughts and rituals that constituted the list of symptoms. However, children with AS exhibited a more simplified repertoire of mental states in describing repetitive thoughts and rituals and showed more difficulties in generalizing the examples provided by the investigator during the interview to explain the OC symptoms.

Another limit of the study concerns the relatively small sample size that could have lowered the power to detect statistical differences. Some caution should therefore be raised when generalizing these results.

\section{Conclusion}

The study tried to address the question of whether OC symptoms in AS subjects ought to be considered as a comorbidity according to a categorical approach or whether they may be regarded in some way as a continuum of symptoms across different conditions in a dimensional perspective. In the author's opinion, the sub-threshold OC symptoms detected in our AS sample might be read as the sign of a phenomenological and possibly neurobiological overlap between ASD and OCD according to the concept of a broader spectrum of OC-related disorders, in line with previous bibliography [4]. This model seems sustained by some evidence derived from the association between ASD and OCD in family studies [1, 14] and by some findings from clinical trials of a positive pharmacologic treatment response to SRIs in ASD [15, 24, 25].

Further research is warranted to better understand the characteristics of repetitive thoughts and behaviours in ASD, and to clarify the underlying neurobiological basis of these symptoms.

Acknowledgments The authors thank the children and the families who participated in the study. We are also deeply grateful to Erin Ingudomnukul (Autism Research Centre, Department of Psychiatry, University of Cambridge, Cambridge, UK) and Benjamin C. Gunter (Division of Child \& Adolescent Psychiatry, Columbia University \& New York State Psychiatric Institute, New York, NY, USA) for providing valued comments and editing help. We have no interests to declare.

\section{References}

1. Abramson RK, Ravan SA, Wright HH, Wieduwilt K, Wolpert CM, Donnelly SA, Pericak-Vance MA, Cuccaro ML (2005) The relationship between restrictive and repetitive behaviors in 
individuals with autism and obsessive compulsive symptoms in parents. Child Psychiatry Hum Dev 36(2):155-165

2. American Psychiatric Association (2000) Diagnostic and Statistical Manual of Mental Disorders, 4th edn, Text Revision (DSMIV-TR). American Psychiatric Association, Washington, DC

3. Baron-Cohen S (1989) Do autistic children have obsessions and compulsions? Br J Clin Psychol 28(Pt 3):193-200 Review

4. Bartz JA, Hollander E (2006) Is obsessive-compulsive disorder an anxiety disorder? Prog Neuropsychopharmacol Biol Psychiatry 30(3):338-352

5. Bejerot S (2007) An autistic dimension: a proposed subtype of obsessive-compulsive disorder. Autism 11(2):101-110

6. Bejerot S, Nylander L, Lindström E (2001) Autistic traits in obsessive-compulsive disorder. Nord J Psychiatry 55(3):169-176

7. Bodfish JW, Symons FJ, Parker DE, Lewis MH (2000) Varieties of repetitive behavior in autism: comparisons to mental retardation. J Autism Dev Disord 30(3):237-243

8. Carcani-Rathwell I, Rabe-Hasketh S, Santosh PJ (2006) Repetitive and stereotyped behaviours in pervasive developmental disorders. J Child Psychol Psychiatry 47(6):573-581

9. Cath DC, Ran N, Smit JH, van Balkom AJ, Comijs HC (2008) Symptom overlap between autism spectrum disorder, generalized social anxiety disorder and obsessive-compulsive disorder in adults: a preliminary case-controlled study. Psychopathology 41(2):101-110

10. Frith U (1989) Autism: explaining the enigma. Blackwell, Oxford

11. Frost RO, Steketee G (1998) Hoarding: clinical aspects and treatment strategies. In: Jenike MA, Baer L, Minichiello WE (eds) Obsessive compulsive disorder: practical management, 3rd edn. Mosby, St. Louis, pp 533-554

12. Geller DA (2006) Obsessive-compulsive and spectrum disorders in children and adolescents. Psychiatr Clin North Am 29(2):353370 Review

13. Gillberg C, Gillberg C, Rastam M, Wentz E (2001) The Asperger Syndrome (and high-functioning autism) Diagnostic Interview (ASDI): a preliminary study of a new structured clinical interview. Autism 5(1):57-66

14. Hollander E, King A, Delaney K, Smith CJ, Silverman JM (2003) Obsessive-compulsive behaviors in parents of multiplex autism families. Psychiatry Res 117(1):11-16

15. Hollander E, Phillips A, Chaplin W, Zagursky K, Novotny S, Wasserman S, Iyengar R (2005) A placebo controlled crossover trial of liquid fluoxetine on repetitive behaviors in childhood and adolescent autism. Neuropsychopharmacology 30(3):582-589

16. Ivarsson T, Melin K (2008) Autism spectrum traits in children and adolescents with obsessive-compulsive disorder (OCD). J Anxiety Disord 22(6):969-978. doi:10.1016/j.janxdis.2007. 10.003

17. Kanner L (1943) Autistic disturbances of affective contact. Nervous Child 2:217-250 [Reprinted in Childhood psychosis: Initial studies and new insights, ed. Leo Kanner (Washington, DC: V. H. Winston, 1973). Also reprinted in Classic readings in autism, ed. Anne M. Donnellan (New York: Teacher's College Press, 1985)

18. Kaufman J, Birmaher B, Brent D, Rao U, Flynn C, Moreci P, Williamson D, Ryan N (1997) Schedule for Affective Disorders and Schizophrenia for School-Age Children-Present and Lifetime Version (K-SADS-PL): initial reliability and validity data. J Am Acad Child Adolesc Psychiatry 36(7):980-988

19. Lehmkuhl HD, Storch EA, Bodfish JW, Geffken GR (2007) Brief report: exposure and response prevention for obsessive compulsive disorder in a 12-year-old with autism. J Autism Dev Disord 38(5):977-981. doi:10.1007/s10803-007-0457-2

20. Lord C, Rutter M, Goode S, Heemsbergen J, Jordan H, Mawhood L, Schopler E (1989) Autism diagnostic observation schedule: a standardized observation of communicative and social behaviour. J Autism Dev Disord 19(2):185-212

21. Lord C, Rutter M, Le Couteur A (1994) Autism Diagnostic Interview-Revised: a revised version of a diagnostic interview for caregivers of individuals with possible pervasive developmental disorders. J Autism Dev Disord 24:659-685

22. Marazziti D, Dell'Osso L, Di Nasso E, Pfanner C, Presta S, Mungai F, Cassano GB (2002) Insight in obsessive-compulsive disorder: a study of an Italian sample. Eur Psychiatry 17(7):407410

23. McDougle CJ, Kresch LE, Goodman WK, Naylor ST, Volkmar FR, Cohen DJ, Price LH (1995) A case-controlled study of repetitive thoughts and behaviour in adults with autistic disorder and obsessive-compulsive disorder. Am J Psychiatry 152(5):772777

24. McDougle CJ, Naylor ST, Cohen DJ, Volkmar FR, Heninger GR, Price LH (1996) A double-blind, placebo-controlled study of fluvoxamine in adults with autistic disorder. Arch Gen Psychiatry 53(11):1001-1008

25. McDougle CJ, Kresch LE, Posey DJ (2000) Repetitive thoughts and behaviour in pervasive developmental disorders: treatment with serotonin reuptake inhibitors. J Autism Dev Disord 30(5):427-435

26. Militerni R, Bravaccio C, Falco C, Fico C, Palermo MT (2002) Repetitive behaviours in autistic disorder. Eur Child Adolesc Psychiatry 11(5):210-218

27. Piacentini J, Bergman RL, Keller M, McCracken J (2003) Functional impairment in children and adolescents with obsessive-compulsive disorder. J Child Adolesc Psychopharmacol 13(Suppl 1):S61-S69

28. Rapoport JL, Swedo SE, Leonard HL (1992) Childhood obsessive-compulsive disorder. J Clin Psychiatry 53:11-16

29. Russell AJ, Mataix-Cols D, Anson M, Murphy DG (2005) Obsessions and compulsions in Asperger syndrome and highfunctioning autism. Br J Psychiatry 186:525-528

30. Scahill L, Riddle MA, McSwiggin-Hardin M, Ort SI, King RA, Goodman WK, Cicchetti D, Leckman JF (1997) Children's YaleBrown Obsessive Compulsive Scale: reliability and validity. J Am Acad Child Adolesc Psychiatry 36(6):844-852

31. South M, Ozonoff S, McMahon WM (2005) Repetitive behaviour profiles in Asperger syndrome and high-functioning autism. J Autism Dev Disord 35(2):145-158

32. Storch EA, Milsom VA, Merlo LJ, Larson M, Geffken GR, Jacob ML, Murphy TK, Goodman WK (2008) Insight in pediatric obsessive-compulsive disorder: associations with clinical presentation. Psychiatry Res 160(2):212-220

33. Turner M (1999) Annotation: repetitive behaviour in autism: a review of psychological research. J Child Psychol Psychiatry 40(6):839-849 Review

34. Wechsler D (1974) Manual for the Wechsler Intelligence Scale for Children-Revised. The Psychological Corporation, San Antonio

35. World Health Organization (1992) The ICD-10 classification of mental and behavioural disorders. WHO, Geneva

36. Zandt F, Prior M, Kyrios M (2007) Repetitive behaviour in children with high functioning autism and obsessive compulsive disorder. J Autism Dev Disord 37(2):251-259 